\title{
Involvement of tissue bacteria in the onset of diabetes in humans: evidence for a concept
}

\author{
J. Amar • M. Serino $\cdot$ C. Lange $\cdot$ C. Chabo $\cdot$ \\ J. Iacovoni $\cdot$ S. Mondot $\cdot$ P. Lepage $\cdot$ C. Klopp . \\ J. Mariette $\cdot$ O. Bouchez $\cdot$ L. Perez $\cdot$ M. Courtney • \\ M. Marre • P. Klopp • O. Lantieri • J. Doré • \\ M. A. Charles $\cdot$ B. Balkau $\cdot$ R. Burcelin • \\ for the D.E.S.I.R. Study Group
}

Received: 21 June 2011 /Accepted: 9 September 2011 /Published online: 6 October 2011

(C) Springer-Verlag 2011

\begin{abstract}
Aims/hypothesis Evidence suggests that bacterial components in blood could play an early role in events leading to diabetes. To test this hypothesis, we studied the capacity of
\end{abstract}

J. Amar and M. Serino contributed equally to this study.

Electronic supplementary material The online version of this article (doi:10.1007/s00125-011-2329-8) contains peer-reviewed but unedited supplementary material, including a list of D.E.S.I.R. Study Group investigators which is available to authorised users.

J. Amar $(\bowtie)$

Inserm U1027, University Paul Sabatier, CHU, Hôpital Rangueil,

Avenue Jean Pouhles,

Toulouse, France

e-mail: amar.j@chu-toulouse.fr

M. Serino $\cdot$ C. Chabo $\cdot$ J. Iacovoni $\cdot$ L. Perez $\cdot$ P. Klopp $\cdot$

R. Burcelin

Bio-Medical Research Federative Institute of Toulouse,

Toulouse, France

M. Serino $\cdot$ C. Chabo $\cdot$ J. Iacovoni $\cdot$ L. Perez $\cdot$ P. Klopp .

R. Burcelin $(\bowtie)$

U1048 Institut de Recherche sur les Maladies Métaboliques

et Cardiovasculaires,

CHU Rangueil,

BP 84225, 31432 Toulouse, France

e-mail: remy.burcelin@inserm.fr

C. Lange $\cdot$ M. A. Charles $\cdot$ B. Balkau

Inserm, CESP Centre for Research in Epidemiology

and Population Health, U1018, Epidemiology of Diabetes,

Obesity and Chronic Kidney Disease over the Lifecourse,

Villejuif, France

C. Lange $\cdot$ M. A. Charles $\cdot$ B. Balkau

University Paris Sud 11, UMRS 1018, Faculty of Medicine,

Villejuif, France a broadly specific bacterial marker (16S rDNA) to predict the onset of diabetes and obesity in a general population. Methods Data from an Epidemiological Study on the Insulin Resistance Syndrome (D.E.S.I.R.) is a longitudinal

\footnotetext{
S. Mondot $\cdot$ P. Lepage $\cdot J$. Doré

INRA UMR1319,

Jouy-en-Josas, France

C. Klopp · J. Mariette

Bio-informatic Platform Toulouse Genopole, UBIA INRA,

Castanet-Tolosan, France

O. Bouchez

Genotoul Platform, INRA,

Auzeville, France

M. Courtney

VAIOMER SAS,

Toulouse, France

M. Marre

Service d'Endocrinologie-Diabète-Nutrition, Groupe Hospitalier Bichat-Claude Bernard, Assistance Publique des Hôpitaux de Paris, Paris, France

M. Marre

Inserm U695, Université Denis Diderot Paris,

Paris, France

O. Lantieri

IRSA,

La Riche, France
} 
study with the primary aim of describing the history of the metabolic syndrome. The 16S rDNA concentration was measured in blood at baseline and its relationship with incident diabetes and obesity over 9 years of follow-up was assessed. In addition, in a nested case-control study in which participants later developed diabetes, bacterial phylotypes present in blood were identified by pyrosequencing of the overall $16 \mathrm{~S}$ rDNA gene content.

Results We analysed 3,280 participants without diabetes or obesity at baseline. The $16 \mathrm{~S}$ rDNA concentration was higher in those destined to have diabetes. No difference was observed regarding obesity. However, the $16 \mathrm{~S}$ rDNA concentration was higher in those who had abdominal adiposity at the end of follow-up. The adjusted OR (95\% CIs) for incident diabetes and for abdominal adiposity were $1.35(1.11,1.60), p=0.002$ and $1.18(1.03,1.34), p=0.01$, respectively. Moreover, pyrosequencing analyses showed that participants destined to have diabetes and the controls shared a core blood microbiota, mostly composed of the Proteobacteria phylum (85-90\%).

Conclusions/interpretation 16S rDNA was shown to be an independent marker of the risk of diabetes. These findings are evidence for the concept that tissue bacteria are involved in the onset of diabetes in humans.

Keywords Abdominal adiposity . Microbiota . Obesity . 16S rDNA gene

$\begin{array}{ll}\text { Abbreviations } \\ \text { D.E.S.I.R } & \begin{array}{l}\text { Data from an Epidemiological Study on } \\ \text { the Insulin Resistance Syndrome }\end{array} \\ \text { MID } & \text { Multiplex identifier } \\ \text { OTU } & \text { Operational taxonomic diversity unit }\end{array}$

\section{Introduction}

The incidence of diabetes, in developed and emerging countries, has reached epidemic proportions [1]. A body of evidence demonstrates that the intestinal microbiota, which correspond to the overall bacterial community present in the intestine, play a role in the onset of metabolic disease [2-4]. The causal role of the intestinal microbiota in weight gain has been demonstrated in animal models [2]. In humans, obesity is associated with changed phylum levels in the gut microbiota [3]. In addition, the role of bacterial components in blood has also been demonstrated: thus, mice chronically infused with a low dose of lipopolysaccharides developed inflammation and diabetes [4]. Importantly, the plasma lipopolysaccharides concentration has been found to predict the onset of diabetes [5]. From these data, we hypothesised that the presence of a blood microbiome could be one of the initial steps leading to diabetes and obesity. To test this hypothesis, we investigated whether the 16S rDNA concentration in blood could be a marker of the risk of diabetes and obesity in a large general population. We studied this gene as it is highly conserved between different species of bacteria and is hence considered to be a marker of the overall microbiota [6]. Moreover, by pyrosequencing the overall 16S rDNA gene population in blood, we determined the profile of bacteria present in individuals who were destined to develop diabetes versus those present in controls.

\section{Methods}

Study overview Data from an Epidemiological Study on the Insulin Resistance Syndrome (D.E.S.I.R.) is a longitudinal cohort study of 5,212 adults aged 30 to 65 years at baseline; the primary aim of the study was to describe the natural history of the metabolic syndrome [7]. Participants were recruited between 1994 and 1996 from volunteers insured by the French national social security system in ten social security health examination centres. All participants gave written informed consent and the study protocol was approved by the Comité Consultatif de Protection des Personnes pour la Recherche Biomédicale of the Hôpital Bicêtre (Paris, France). Participants were clinically and biologically evaluated at inclusion and at follow-up visits in years 3, 6 and 9. We measured the baseline 16S rDNA concentration in individuals without diabetes (defined by treatment for diabetes or fasting plasma glucose $\geq 7.0 \mathrm{mmol} / \mathrm{l}$ ) or obesity (BMI $\geq 30 \mathrm{~kg} / \mathrm{m}^{2}$ ) at baseline and in those who had a known diabetes status at the year 9 examination. We excluded those who were likely to have a current infection (C-reactive protein $>10 \mathrm{mg} / \mathrm{l}$, abundant leucocyturia) or who were taking antiviral therapy.

Variables studied Weight and height were measured in lightly clad participants and BMI was calculated. Waist circumference, i.e. the smallest circumference between the lower ribs and the iliac crests, was also measured. The examining physician noted the existence of a family history of diabetes, and treatments for diabetes and hypertension were recorded. Hypertension was defined as a systolic/ diastolic blood pressure of at least $140 / 90 \mathrm{mmHg}$ or taking antihypertensive medication. Smoking habits were documented in a questionnaire filled in by the participants. Central adiposity was defined as a waist circumference $\geq 102 \mathrm{~cm}$ in men and $\geq 88 \mathrm{~cm}$ in women, while high fasting glucose was defined as $\geq 6.1 \mathrm{mmol} / 1$ [8].

Biological analyses Blood was drawn after a $12 \mathrm{~h}$ fast. The methods used for biological analyses, except for bacterial DNA preparation and analysis, have been described elsewhere [7]. 
Bacterial DNA preparation DNA was extracted from peripheral blood leucocytes using a classical phenol/chloroform extraction method followed by alcohol precipitation (icecold $70 \%$ alcohol by vol.). Air-dried DNA was resuspended in TRIS EDTA and stored at $-80^{\circ} \mathrm{C}$ before use at a concentration of $1 \mu \mathrm{g} / \mu \mathrm{l}[9,10]$. It is noteworthy that this method did not use glass microbeads to increase the efficiency of bacterial DNA extraction, as commonly done in current methods. The reason for this was that isolation of bacterial DNA was not the goal of the work at the time of the sample preparation. However, despite this important technical difference, we succeeded in amplifying $16 \mathrm{~S}$ rDNA from blood. To validate the difference between both extraction procedures, we extracted total blood DNA in the presence or absence of microbeads. The efficacy of bacterial DNA extraction, as assessed by $16 \mathrm{~S}$ rDNA quantitative PCR amplification, was ten times greater when using microbeads. Although the absolute value of the bacterial DNA concentration was higher, the proportion between samples remained the same.

Quantification of $16 \mathrm{~S}$ rDNA The total DNA concentration was determined using a broad-range assay kit (Quant-iT dsDNA; Life Technologies, Villebon-sur-Yvette, France). The mean concentration $\pm \mathrm{SD}$ was $121.1 \pm 208.3 \mathrm{ng} / \mu \mathrm{l}$. Each sample was diluted tenfold in TRIS buffer EDTA. The DNA was amplified by real-time PCR (Life Technologies) in optical-grade 96-well plates. The PCR reaction was performed in a total volume of $25 \mu \mathrm{l}$ using a master mix (Power SYBR Green PCR; Life Technologies) containing $300 \mathrm{nmol} / \mathrm{l}$ of each of the universal forward and reverse primers for Eubact: forward 5'-TCCTACGGGAGGCAGCAGT-3' and reverse 5'GGACTACCAGGGTATCTAATCCTGTT-3'. The reaction conditions for amplification of DNA were $95^{\circ} \mathrm{C}$ for $10 \mathrm{~min}$, and 35 cycles at $95^{\circ} \mathrm{C}$ for $15 \mathrm{~s}$ and at $60^{\circ} \mathrm{C}$ for $1 \mathrm{~min}$. The amplification step was followed by a melting curve step according to the manufacturer's instructions (from $60^{\circ} \mathrm{C}$ to $90^{\circ} \mathrm{C}$ ) to determine the specificity of the amplification product obtained. The amount of amplified DNA was determined using a $16 \mathrm{~S}$ rDNA standard curve obtained by real-time PCR from dilutions ranging from 0.001 to $10 \mathrm{ng} / \mu \mathrm{l}$ of $E$. coli BL21 DNA.

Identification of bacterial sequences This sub-study included 14 participants with incident diabetes at year 9, but who had been at low risk of diabetes at baseline, having been non-smokers with a waist perimeter of $<85 \mathrm{~cm}$ for men and $<75 \mathrm{~cm}$ for women. These 14 participants were matched for age ( \pm 3 years), sex, waist circumference $( \pm 3 \mathrm{~cm})$ and fasting blood glucose $( \pm 0.3 \mathrm{mmol} / \mathrm{l})$ with 28 control participants who remained free of diabetes over the entire follow-up period. The V1-V2 variable region of the $16 \mathrm{~S}$ rDNA gene was amplified by PCR for each participant, and amplicons from case and control participants were pooled separately after size verification by $2 \%$ agarose gel electrophoresis. Each pool was assigned to specific multiplex identifiers (MIDs) that were used as tags. These two pools of amplicons were pyrosequenced using a genome sequencer (454 Life Sciences; Branford, CT, USA) on a multiplexed pyrosequencing run (GS FLX-Ti; Life Technology). Sequences were binned for removal of pyrosequencing MIDs and PCR primers (forward: AG-AGT-TTG-ATC-MTG-GCTCAG; reverse: GC-TGC-CTC-CCG-TAG-GAG-T) [2, 3]. Meta RNA software, designed for the identification of $16 \mathrm{~S}$ rRNA sequences based on hidden Markov models, was further applied to select prokaryotic 16S rRNA sequences [11]. The resulting $16 \mathrm{~S}$ rRNA sequences were assigned to taxonomies using mothur software [12] and the SILVA reference taxonomic outline [13].

Bioinformatic analyses of the 919,095 and 768,245 sequence reads recovered for case and control participants respectively, $\sim 30 \%$ were removed by initial quality filters. A de-noising step was performed to remove most of the common sequencing errors encountered with the 454 platform by clustering chimeric sequences as well as reads that were most likely to have been derived from the same sequence.

Statistical analyses For statistical analysis, in order to carry out parametric tests, the $16 \mathrm{~S}$ rDNA concentrations were logtransformed, as the distribution was skewed (as were levels of triacylglycerol and insulin). The characteristics of the participants who did and did not have incident diabetes over followup are shown and compared by $t$ and $\chi^{2}$ tests. Note that logtransformed 16S rDNA concentrations were compared statistically. For incident diabetes and abdominal adiposity, logistic regression was used to calculate the standardised odds ratios and $95 \%$ CIs for an increase of one SD of baseline $16 \mathrm{~S}$ rDNA concentration as a continuous variable (logarithm). Adjustments were made for sex, baseline age, family history of diabetes, hypertension, waist circumference, BMI, smoking status and fasting plasma glucose. The relationship with $16 \mathrm{~S}$ rDNA concentration was linear, as an additional squared term was not significant. ORs were also calculated over risk factor strata. The $\mathrm{C}$ statistic was used to quantify the discriminative ability of $16 \mathrm{~S}$ rDNA and that of various risk factors for diabetes. SAS versions 9.1 and 9.2 (Cary, NC, USA) were used for statistical analysis.

\section{Results}

Characteristics of the population studied At baseline, of the 5,212 participants in the D.E.S.I.R. study, 126 had diabetes, 474 were obese, 65 had biological signs of infection or were taking antiviral therapy, and 333 did not undergo $16 \mathrm{~S}$ 
rDNA concentration determination. For 1,146 participants, the diabetes status was not known at the end of the 9 years, as they did not attend the year 9 examination. These volunteers were excluded from the analysis. By comparison, the participants analysed $(n=3,280)$ were older and fewer were current smokers. There was no significant difference in baseline 16S rDNA gene concentrations, waist circumference or fasting plasma glucose. The characteristics of the study population are shown in Table 1; 131 incident cases of diabetes were recorded. The mean $16 \mathrm{~S}$ rDNA concentration was higher in those with incident diabetes (Table 2) and the distribution of log-transformed 16S rDNA concentration was shifted to the right (Fig. 1). No difference in baseline blood 16S rDNA concentration was observed in participants destined to become obese. In contrast, mean baseline $16 \mathrm{~S}$ rDNA concentration (log-transformed) tended to be higher (mean \pm standard deviation $-2.73 \pm 1.04$ vs $-2.63 \pm 1.04 ; n=485 ; p=0.05$ ) in those who were to present with abdominal adiposity after 9 years of follow-up. A bivariate analysis between blood bacterial DNA and other biological variables showed a modest negative correlation with fasting blood glucose, while a positive correlation with fibrinogen and leucocyte count was observed (Table 3).

Prediction of diabetes and abdominal adiposity The 16S rDNA concentration predicted the onset of diabetes after adjustment for confounding factors, with a standardised OR of $1.29(95 \%$ CI $1.08,1.55)$ after adjustment for age, sex and fasting blood glucose, and of 1.35 (95\% CI 1.11, 1.64) in a fully adjusted model (Table 3). While higher $16 \mathrm{~S}$ rDNA concentrations appeared to carry more risk in women and in those with lower fasting glucose, there was no significant difference between strata for the risk of incident diabetes between bacterial DNA and any of these strata

Table 1 Socio-demographic and other characteristics of study population

\begin{tabular}{llll}
\hline Variable & No diabetes & Incident diabetes & $p$ value \\
\hline Total $(n)$ & 3,149 & 131 & \\
Women, $n(\%)$ & $1,633(52)$ & $33(25)$ & 0.0001 \\
Diabetes in family, $n(\%)$ & $574(18)$ & $30(23)$ & 0.2 \\
Current smoker, $n(\%)$ & $586(19)$ & $36(27)$ & 0.01 \\
Hypertension, $n(\%)^{\mathrm{a}}$ & $984(31)$ & $71(54)$ & 0.0001 \\
Education level, $n(\%)$ & & & 0.4 \\
High school or higher & $786(25)$ & $27(20)$ & \\
Trade qualification & $1,954(63)$ & $84(65)$ & \\
No qualification & $372(12)$ & $19(15)$ & \\
\hline
\end{tabular}

${ }^{\mathrm{a}}$ Systolic $\mathrm{BP} \geq 140 \mathrm{mmHg}$ and/or diastolic $\mathrm{BP} \geq 90 \mathrm{mmHg}$ and/or antihypertensive treatment

${ }^{\mathrm{b}}{ }_{n=38}$ missing data
(Table 4). We also analysed the risk of developing diabetes by follow-up time. The OR of developing diabetes was higher in participants who developed diabetes within the 6 to 9 year window (OR 1.61, 95\% CI 1.23, 2.10; $p=0.0005$ ) than in those who developed diabetes soon after the initial measurement, i.e. in the 0 to 3 year window (OR 1.10, 95\% CI $0.87,1.39 ; p=0.45$ ). On its own, $16 \mathrm{~S}$ rDNA as a marker carried little discriminative ability between those who did and did not develop incident diabetes, with a $\mathrm{C}$ statistic of 0.564 ; however, when the level of $16 \mathrm{~S}$ rDNA was added to a predictive score for diabetes derived in the D.E.S.I.R. population [14], the $\mathrm{C}$ statistic increased significantly from 0.862 to $0.871(p=0.02)$ and $16 \mathrm{~S}$ rDNA was still predictive of diabetes after adjustment for this score $(p=0.004)$

The 16S rDNA concentration also predicted the presence of abdominal adiposity at the end of 9 years, after adjustment for confounders, with a standardised OR of $1.18(95 \%$ CI $1.03,1.34 ; p=0.01)$.

Identification of blood bacteria phyla in participants with incident diabetes The 16S rDNA gene was sequenced in the pooled baseline DNA samples from participants destined to become diabetic and from controls. We first analysed the alpha diversity, which corresponds to groups of sequences characterised by less than $10 \%$ differences. Each group of similar sequences defines an operational taxonomic diversity unit (OTU). The number of OTUs (at 10\%) was 745 and 800 in cases and controls, respectively (see electronic supplementary material [ESM] Fig. 1). A common core of 443 OTUs was identified. At the phylum level, proteobacteria represented $80 \%$ to $90 \%$ of all phyla in the blood, both in cases and controls (Fig. 2). Within the Proteobacteria phylum, at a genera level, the Ralstonia genus was the most prevalent (see ESM Fig. 2).

\section{Discussion}

We show, for the first time, that the blood concentration of a bacterial gene predicts the onset of diabetes, particularly 6 to 9 years after baseline, and also predicts abdominal adiposity in a large sample of non-obese participants from a general population. We found that more than $90 \%$ of this bacterial DNA belonged to the Proteobacteria phylum.

The involvement of inflammation in the development of insulin resistance [14-16] and the pro-inflammatory effects of bacterial components present within tissues [4] suggest that the role played by tissue bacteria in relation to diabetes and its complications should be explored. Indeed, experimental data have already linked the metabolic syndrome with gut microbiota and innate immunity against infectious 
Table 2 Laboratory and other characteristics of study population

\begin{tabular}{|c|c|c|c|c|c|c|c|c|c|}
\hline \multirow[t]{2}{*}{ Variable } & \multicolumn{4}{|l|}{ No diabetes } & \multicolumn{4}{|c|}{ Incident diabetes } & \multirow[t]{2}{*}{$p$ value } \\
\hline & Mean \pm SD & Median & 1st quartile & 3rd quartile & Mean \pm SD & Median & 1st quartile & 3rd quartile & \\
\hline Age (years) & $47 \pm 10$ & 46 & 38 & 55 & $51 \pm 9$ & 52 & 43 & 59 & 0.0001 \\
\hline BMI $\left(\mathrm{kg} / \mathrm{m}^{2}\right)$ & $23.8 \pm 2.8$ & 23.77 & 21.80 & 25.91 & $25.8 \pm 2.5$ & 25.99 & 24.46 & 27.70 & 0.0001 \\
\hline \multicolumn{10}{|l|}{ Waist (cm) } \\
\hline Men & $88 \pm 8$ & 88 & 82 & 93 & $92 \pm 7$ & 93 & 87 & 98 & 0.0001 \\
\hline Women & $75 \pm 8$ & 74 & 69 & 80 & $83 \pm 7$ & 85 & 78 & 89 & 0.0001 \\
\hline Glucose $(\mathrm{mmol} / \mathrm{l})$ & $5.23 \pm 0.49$ & 5.20 & 4.88 & 5.54 & $6.07 \pm 0.55$ & 6.11 & 5.70 & 6.47 & 0.0001 \\
\hline $\mathrm{HbA}_{1 \mathrm{c}}(\%)$ & $5.39 \pm 0.38$ & 5.39 & 5.18 & 5.66 & $5.83 \pm 0.51$ & 5.77 & 5.56 & 6.15 & 0.0001 \\
\hline $\mathrm{HbA}_{1 \mathrm{c}}(\mathrm{mmol} / \mathrm{mol})$ & $35.44 \pm 4.14$ & 24.46 & 25.99 & 27.70 & $40.19 \pm 5.61$ & 37.30 & 39.61 & 43.72 & $<0.0001$ \\
\hline Total cholesterol (mmol/l) & $5.69 \pm 0.97$ & 5.65 & 5.03 & 6.32 & $6.01 \pm 1.10$ & 5.96 & 5.21 & 6.66 & 0.0002 \\
\hline Triacylglycerol $(\mathrm{mmol} / \mathrm{l})^{\mathrm{a}}$ & $1.06 \pm 0.65$ & 0.90 & 0.65 & 1.28 & $1.63 \pm 1.42$ & 1.29 & 0.97 & 1.78 & \\
\hline Insulin $(\mathrm{pmol} / \mathrm{l})^{\mathrm{a}}$ & $41.80 \pm 21.40$ & 37.14 & 27.46 & 50.62 & $61.16 \pm 35.67$ & 51.70 & 36.28 & 79.52 & \\
\hline HOMA B ${ }^{b}$ & $83.35 \pm 25.73$ & 78.90 & 65.40 & 96.30 & $79.01 \pm 32.59$ & 72.70 & 55.90 & 98.60 & 0.0009 \\
\hline HOMA IR ${ }^{b}$ & $0.97 \pm 0.45$ & 0.90 & 0.70 & 1.10 & $1.41 \pm 0.76$ & 1.20 & 0.90 & 1.80 & 0.0001 \\
\hline Fibrinogen $(\mathrm{g} / \mathrm{l})$ & $2.93 \pm 0.61$ & 2.85 & 2.49 & 3.26 & $3.15 \pm 0.71$ & 3.04 & 2.55 & 3.65 & 0.0001 \\
\hline Leucocyte count $(\mathrm{g} / \mathrm{l})^{\mathrm{a}, \mathrm{c}}$ & $63 \pm 17$ & 60 & 52 & 71 & $67 \pm 20$ & 64 & 53 & 77 & 0.002 \\
\hline 16S rDNA gene $(\mathrm{ng} / \mu \mathrm{l})$ & $0.13 \pm 0.27$ & 0.057 & 0.032 & 0.120 & $0.15 \pm 0.25$ & 0.076 & 0.042 & 0.141 & \\
\hline Log 16S rDNA gene $(\mathrm{ng} / \mu \mathrm{l})$ & $-2.72 \pm 1.05$ & & & & $-2.53 \pm 1.00$ & & & & 0.04 \\
\hline
\end{tabular}

${ }^{\mathrm{a}} n=38$ missing data

${ }^{b}$ The HOMA of beta cell function (HOMA B) and of insulin resistance (HOMA IR) was computed using software downloaded from www.dtu.ox.ac.uk ${ }^{\mathrm{c}} 10^{2} / \mathrm{mm}^{3}$

diseases [3, 4]. We [4, 17, 18] and others [3] have demonstrated the influence of gut microbiota on metabolic disease in animal models. Consistently, in humans, periodontitis, a chronic gram-negative infectious disease of the oral cavity, has been associated with the metabolic syndrome [19-23]. In line with these data, the longitudinal study reported here provides for the first time evidence of the involvement of tissue microbiota in the development of diabetes in humans.

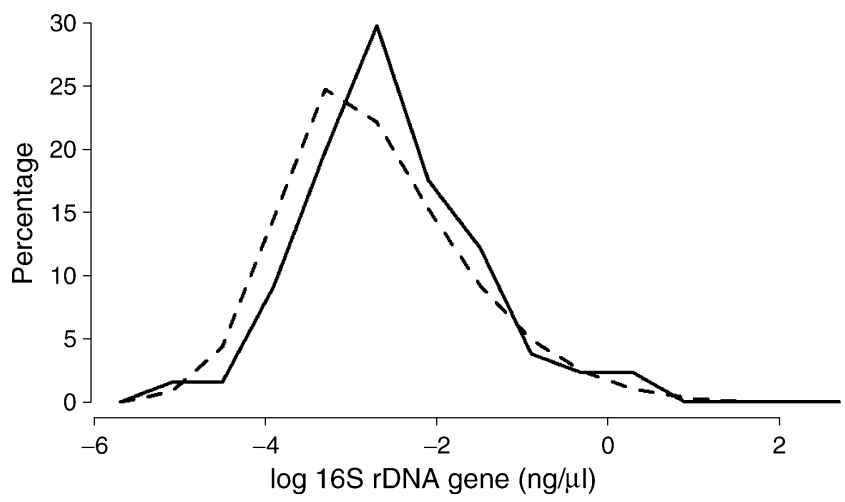

Fig. 1 Distribution of participants destined to become diabetic (continuous line) and those who did not (dotted line) according to baseline blood 16S rDNA gene concentration
These epidemiological data also provide some insight into the mechanisms of action of the microbiota. Indeed, although no difference was observed in blood microbiota composition in participants destined to develop diabetes and in controls, possibly because of a lack of statistical power, we did establish the predominance of proteobacteria, which represent $90 \%$ of overall microbiota. In this respect, the role of lipopolysaccharides, a major component of proteobacteria, in the onset of diabetes has already been

Table 3 Correlation coefficients between blood bacterial DNA gene concentration and other biological variables

\begin{tabular}{lll}
\hline Variable & $r$ & $p$ value \\
\hline Fasting blood glucose (mmol/l) & -0.04 & 0.02 \\
Insulin (pmol/l) & -0.0013 & 0.94 \\
HOMA B & -0.0047 & 0.80 \\
HOMA IR & -0.033 & 0.07 \\
Fibrinogen $(\mathrm{g} / \mathrm{l})$ & 0.158 & $<0.0001$ \\
Leucocyte count $(\mathrm{g} / \mathrm{l})$ & 0.041 & 0.02 \\
\hline
\end{tabular}

Values are Spearman's rank correlation; $n=891$

The HOMA of beta cell function (HOMA B) and of insulin resistance (HOMA IR) was computed using software downloaded from www. dtu.ox.ac.uk 
Table 4 Adjusted ORs (95\% CI) of incident diabetes for 1 SD of $\log$ (16S rDNA gene concentration) in the overall population and in various strata

\begin{tabular}{|c|c|c|c|c|}
\hline Variable & $\begin{array}{l}\text { Incident } \\
\text { diabetes }(n)\end{array}$ & $\mathrm{OR}^{\mathrm{a}}$ & $95 \% \mathrm{CI}$ & $p$ value \\
\hline Overall & 131 & 1.35 & $1.11,1.64$ & 0.002 \\
\hline \multicolumn{5}{|l|}{ Sex } \\
\hline Women & 33 & 1.56 & $1.05,2.33$ & 0.03 \\
\hline Men & 98 & 1.29 & $1.04,1.61$ & 0.02 \\
\hline \multicolumn{5}{|l|}{ Median age (years) } \\
\hline$\leq 46$ & 48 & 1.47 & $1.06,2.04$ & 0.02 \\
\hline$>46$ & 83 & 1.31 & $1.03,1.67$ & 0.03 \\
\hline \multicolumn{5}{|l|}{ Abdominal adiposity } \\
\hline Absent & 116 & 1.37 & $1.12,1.66$ & 0.003 \\
\hline Present & 15 & 1.28 & $0.70,2.33$ & 0.43 \\
\hline \multicolumn{5}{|l|}{ Smoking status } \\
\hline Non-smokers & 95 & 1.36 & $1.09,1.70$ & 0.006 \\
\hline Current smokers & 36 & 1.36 & $0.90,2.03$ & 0.1 \\
\hline \multicolumn{5}{|l|}{ Education level ${ }^{\mathrm{a}, \mathrm{b}}$} \\
\hline No qualification & 19 & 1.48 & $0.87,2.52$ & 0.15 \\
\hline Trade qualification & 84 & 1.38 & $1.08,1.77$ & 0.01 \\
\hline High school or higher & 27 & 1.35 & $0.90,2.02$ & 0.14 \\
\hline \multicolumn{5}{|l|}{ Diabetes in family } \\
\hline Absent & 101 & 1.24 & $0.99,1.54$ & 0.06 \\
\hline Present & 30 & 1.92 & $1.26,2.94$ & 0.002 \\
\hline \multicolumn{5}{|l|}{ Hypertension } \\
\hline Absent & 60 & 1.55 & $1.16,2.05$ & 0.003 \\
\hline Present & 71 & 1.23 & $0.94,1.61$ & 0.13 \\
\hline \multicolumn{5}{|l|}{ High fasting glucose } \\
\hline Absent & 64 & 1.36 & $1.08,1.72$ & 0.009 \\
\hline Present & 67 & 1.15 & $0.84,1.58$ & 0.38 \\
\hline
\end{tabular}

${ }^{a}$ Adjusted for sex, baseline age, family history of diabetes, smoking status, hypertension, waist circumference, BMI and fasting plasma glucose, except where that variable was being specifically studied: for example, the ORs for sex were not adjusted for sex, those for age not for age, etc

${ }^{\mathrm{b}}$ This analysis was carried out in 3,242 individuals (data missing for 38 participants)

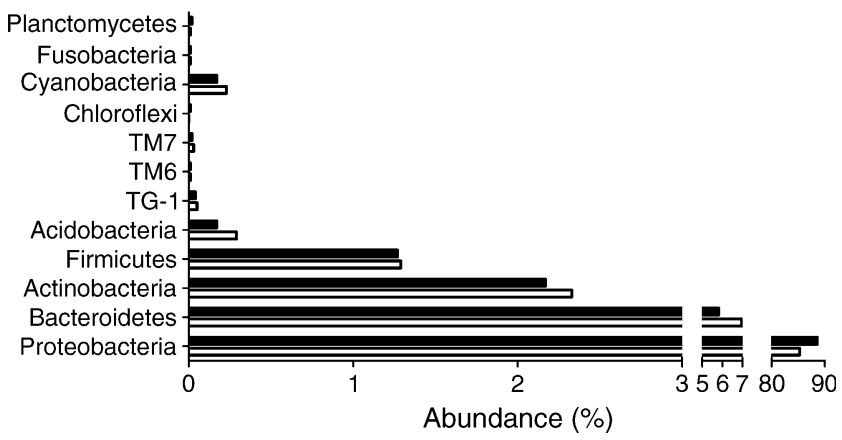

Fig. 2 Abundance of bacterial phyla for those who developed diabetes (black bars) and controls without diabetes over the entire follow-up period (white bars) demonstrated $[3,5]$. Interestingly, in faeces, this phylum is in the minority, since Bacteroidetes and Firmicutes are the most predominant phyla [24], suggesting selectivity of the filtering mechanism, which allows only some bacteria to be present in the blood [17]. From these data, it seems possible that proteobacteria play a role in the onset of metabolic diseases. Our results show at baseline a negative correlation between bacterial DNA levels and fasting blood glucose. At this stage, we cannot rule out a transitory improvement in insulin sensitivity in the early phase of metabolic infection, as shown in an experimental model of gram-negative sepsis in healthy humans $[25,26]$. This could be due to the release of nitric oxide during latent infection, which would in turn improve insulin sensitivity $[27,28]$. On the other hand, the exclusion of patients with treated or non-treated diabetes at baseline, i.e. participants in whom bacteraemia would already have had a deleterious influence on glucose metabolism, is more likely to have contributed to this association. Obviously, the present study is observational in nature and thus cannot demonstrate the causative role played by blood microbiota in the onset of diabetes. Indeed, the blood bacterial DNA burden may only represent an innocent bystander in the disease process. Moreover, these results are preliminary and need to be replicated in other longitudinal data sets.

In conclusion, our results show for the first time that blood microbiota are a marker of the risk of diabetes and abdominal adiposity in a general population. These findings establish evidence for the concept of an involvement of tissue bacteria in the onset of diabetes in humans.

Acknowledgements This work was funded by the Agence Nationale de la Recherche (French national research agency) (to R. Burcelin) and by the Société Francophone de Diabète (to B. Balkau). The D.E.S.I.R. study has been supported by Inserm contracts with CNAMTS, Lilly, Novartis Pharma and sanofi-aventis; by Inserm (Réseaux en Santé Publique, Interactions entre les déterminants de la santé, Cohortes Santé TGIR 2008), the Association Diabète Risque Vasculaire, the Fédération Française de Cardiologie, La Fondation de France, ALFEDIAM, ONIVINS, Société Francophone du Diabète, Ardix Medical, Bayer Diagnostics, Becton Dickinson, Cardionics, Merck Santé, Novo Nordisk, Pierre Fabre, Roche, Topcon.

Contribution statement: JA co-designed the study, contributed to the statistical analyses and interpretation of data, and wrote the first draft of the manuscript. RB co-designed the study, conducted the biological analyses, and contributed to interpretation of data and the writing of the manuscript. BB (principal investigator of the DESIR study) conducted statistical analyses, and contributed to the interpretation of data and to the writing of the manuscript. MS, LP and PK carried out biological analyses, and contributed to the interpretation of data and to the writing of the manuscript. CL carried out statistical analyses, and contributed to interpretation of data and to the writing of the manuscript. CC carried out biological analyses, and contributed to interpretation of data and to the writing of the manuscript. JI carried out bioinformatic analyses, and contributed to interpretation of data and to the writing of the manuscript. SM, PL, CK, JM, OB and JD contributed to pyrosequencing analyses, interpretation of data and the 
writing of the manuscript. MC and MAC contributed to the interpretation of data and the writing of the manuscript. MM created the DNA collection of the D.E.S.I.R. study and contributed to interpretation of data and to the writing of the manuscript. OL researched data, and contributed to interpretation of data and the writing of the manuscript. All authors approved the final version of the manuscript to be published.

Duality of interest J. Amar, R. Burcelin and M. Courtney are major shareholders of VAIOMER, a biotechnology company in the field of metabolic diseases. The remaining authors declare that they have no duality of interest associated with this manuscript.

\section{References}

1. Shaw JE, Sicree RA, Zimmet PZ (2010) Global estimates of the prevalence of diabetes for 2010 and 2030. Diabetes Res Clin Pract 87:4-14

2. Turnbaugh PJ, Ley RE, Mahowald MA, Magrini V, Mardis ER, Gordon JI (2006) An obesity-associated gut microbiome with increased capacity for energy harvest. Nature 444:1027-1031

3. Turnbaugh PJ, Hamady M, Yatsunenko T et al (2009) A core gut microbiome in obese and lean twins. Nature 457:480-484

4. Cani PD, Amar J, Iglesias MA et al (2007) Metabolic endotoxemia initiates obesity and insulin resistance. Diabetes 56:17611772

5. Pussinen PJ, Havulinna AS, Lehto M, Sundvall J, Salomaa V (2011) Endotoxemia is associated with an increased risk of incident diabetes. Diabetes Care 34:392-397

6. Coenye T, Vandamme P (2003) Intragenomic heterogeneity between multiple $16 \mathrm{~S}$ ribosomal RNA operons in sequenced bacterial genomes. FEMS Microbiol Lett 228:45-49

7. Fumeron F, Aubert R, Siddiq A et al (2004) Adiponectin gene polymorphisms and adiponectin levels are independently associated with the development of hyperglycemia during a 3-year period: the epidemiologic data on the insulin resistance syndrome prospective study. Epidemiologic Data on the Insulin Resistance Syndrome (DESIR) Study Group. Diabetes 53:1150-1157

8. Grundy SM, Cleeman JI, Daniels SR et al (2005) American Heart Association; National Heart, Lung, and Blood Institute. Diagnosis and management of the metabolic syndrome: an American Heart Association/National Heart, Lung, and Blood Institute Scientific Statement. Circulation 112:2735-2752

9. Rigat B, Hubert C, Alhenc-Gelas F, Cambien F, Corvol P, Soubrier F (1990) An insertion/deletion polymorphism in the angiotensin I-converting enzyme gene accounting for half the variance of serum enzyme levels. J Clin Invest 86:1343-1346

10. Marcadet A, O'Connell P, Cohen D (1987) Standardized Southern blot workshop technique. In: Dupont B (ed) Histocompatibilty testing, vol 1. Springer, New York, pp 553-560

11. Huang Y, Gilna P, Li W (2009) Identification of ribosomal RNA genes in metagenomic fragments. Bioinformatics 25:1338-1340

12. Schloss PD, Westcott SL, Ryabin T et al (2009) Introducing mothur: open-source, platform-independent, community-supported software for describing and comparing microbial communities. Appl Environ Microbiol 75:7537-7541

13. Pruesse E, Quast C, Knittel K et al (2007) SILVA: a comprehensive online resource for quality checked and aligned ribosomal RNA sequence data compatible with ARB. Nucleic Acids Res 35:7188-7196

14. Balkau B, Lange C, Fezeu L et al (2008) Predicting diabetes: clinical, biological, and genetic approaches: data from the Epidemiological Study on the Insulin Resistance Syndrome (DESIR). Diabetes Care 31:2056-2061

15. Festa A, D'Agostino R Jr, Howard G, Mykkänen L, Tracy RP, Haffner SM (2000) Chronic subclinical inflammation as part of the insulin resistance syndrome: the Insulin Resistance Atherosclerosis Study (IRAS). Circulation 102:42-47

16. Mauras N, Delgiorno C, Kollman C et al (2010) Obesity without established comorbidities of the metabolic syndrome is associated with a proinflammatory and prothrombotic state, even before the onset of puberty in children. J Clin Endocrinol Metab 95:1060 1068

17. Amar J, Chabo C, Waget A et al (2011) Intestinal mucosal adherence and translocation of commensal bacteria at the early onset of type 2 diabetes: molecular mechanisms and probiotic treatment. EMBO Mol Med 3:559-572

18. Cani PD, Bibiloni R, Knauf C et al (2008) Changes in gut microbiota control metabolic endotoxemia-induced inflammation in high-fat diet-induced obesity and diabetes in mice. Diabetes 57:1470-1481

19. Xu H, Barnes GT, Yang Q et al (2003) Chronic inflammation in fat plays a crucial role in the development of obesity-related insulin resistance. J Clin Invest 112:1821-1830

20. D'Aiuto F, Sabbah W, Netuveli G et al (2008) Association of the metabolic syndrome with severe periodontitis in a large U.S. population-based survey. J Clin Endocrinol Metab 93:3989-3994

21. Benguigui C, Bongard V, Ruidavets JB et al (2010) Metabolic syndrome, insulin resistance, and periodontitis: a cross-sectional study in a middle-aged French population. J Clin Periodontol 37:601-608

22. Timonen P, Niskanen M, Suominen-Taipale L, Jula A, Knuuttila M, Ylöstalo P (2010) Metabolic syndrome, periodontal infection, and dental caries. J Dent Res 89:1068-1073

23. Morita T, Yamazaki Y, Mita A et al (2010) A cohort study on the association between periodontal disease and the development of metabolic syndrome. J Periodontol 81:512-519

24. Qin J, Li R, Raes J et al (2010) A human gut microbial gene catalogue established by metagenomic sequencing. Nature 464:59-65

25. Agwunobi AO, Reid C, Maycock P, Little RA, Carlson GL (2000) Insulin resistance and substrate utilization in human endotoxemia. J Clin Endocrinol Metab 85:3770-3778

26. van der Crabben SN, Blümer RM, Stegenga ME et al (2009) Early endotoxemia increases peripheral and hepatic insulin sensitivity in healthy humans. J Clin Endocrinol Metab 94:463-468

27. Perreault M, Marette A (2001) Targeted disruption of inducible nitric oxide synthase protects against obesity-linked insulin resistance in muscle. Nat Med 10:1138-1143

28. Duplain H, Burcelin R, Sartori C et al (2001) Insulin resistance, hyperlipidemia and hypertension in mice lacking endothelial nitric oxide synthase. Circulation 104:342-345 